\title{
When more is less: Extending training of the blocking association following compound training attenuates the blocking effect
}

\author{
OSKAR PINEÑO \\ University of Seville, Seville, Spain \\ KOUJI URUSHIHARA \\ State University of New York, Binghamton, New York \\ STEVEN STOUT \\ Valdosta State University, Valdosta, Georgia \\ and \\ JESSICA FUSS and RALPH R. MILLER \\ State University of New York, Binghamton, New York
}

\begin{abstract}
Three conditioned lick suppression experiments with rats were performed to assess the influence, following compound training of two stimuli (A and $\mathrm{X}$ ) with the same outcome (AX-O trials), of extending training of the blocking association (i.e., A-O) on responding to the target stimulus (X) at test. In Experiment 1, backward blocking was attenuated when the blocking association was extensively trained. Experiment 2 showed that forward blocking was also attenuated by extensive further training of the blocking association following the $\mathrm{AX}-\mathrm{O}$ trials. Experiment 3 contrasted candidate explanations of the results of Experiments 1 and 2 and demonstrated that these results are consistent with the framework of the extended comparator hypothesis (Denniston, Savastano, \& Miller, 2001).
\end{abstract}

Among the various phenomena reported in the associative-learning literature, few have encouraged as much research and development of new models as the blocking effect. In forward blocking (Kamin, 1968), responding to a target conditioned stimulus (CS), X, is impaired due to this CS's receiving pairings with an unconditioned stimulus (US) in compound with a second (blocking) CS, A, that was previously paired with the US on its own. Alternatively stated, the typical forward-blocking design consists of training with two different trial types in separate phases-A-US trials, followed by AX-US trials - and then presenting CS X during testing. The common observation is reduced responding to CS X, relative to a control condition in which pairings of an alternative stimulus (B) and the US are received during the initial phase of training, followed by AX-US trials. In backward

Support for this research was provided by NIMH Grant 33881. The research reported in this article was conducted while O.P. was a postdoctoral fellow at SUNY Binghamton, supported by a grant from the Spanish Ministry of Education (Ref. EX2002-0739). We thank Jeffrey C. Amundson, Gonzalo P. Urcelay, and Daniel S. Wheeler for their comments on an earlier version of the manuscript and James Esposito for his assistance in running the experiments. Special thanks are due Aaron P. Blaisdell for his insightful suggestions concerning an alternative account for our findings. Correspondence concerning this article should be addressed to R. R. Miller, Department of Psychology, SUNY, Binghamton, NY 13902-6000 (e-mail: rmiller@binghamton.edu). blocking (e.g., Shanks, 1985), the order of presentation of the training trials is reversed: AX-US trials are followed by A-US trials and then by testing with CS X. Despite the different trial order, weak responding to CS X is sometimes observed at testing, relative to a control condition in which B-US trials are received in place of the A-US trials. In contrast to forward blocking, which has been consistently observed in different animal species and conditioning paradigms, backward blocking is rather difficult to observe (see Larkin, Aitken, \& Dickinson, 1998; for a discussion, see Miller \& Matute, 1996a).

\section{Associative Models and Backward Blocking: The Role of Within-Compound Associations}

Despite forward- and backward-blocking designs being very similar, traditional theories of associative learning (e.g., Mackintosh, 1975; Pearce \& Hall, 1980; Rescorla \& Wagner, 1972; Wagner, 1981), which successfully explain forward blocking, fail to explain backward blocking. According to these models, training trials with CS A following AX-US trials should have no impact on the status of the previously learned X-US association, because the associative strength of an absent CS is not updated. The observation of backward blocking has prompted investigators who have focused on learning deficits to adapt some traditional models to account for learning about absent CSs (e.g., Dickinson \& Burke, 1996; Markman, 1989; Tassoni, 1995; Van Hamme \& Wasserman, 1994). 
According to Van Hamme and Wasserman's revision of the Rescorla-Wagner model, for example, absent (but expected) CSs adopt a negative salience (i.e., $\alpha$ ) and, hence, change their associative strength in the direction opposite to that of the CSs that are present, which always have a positive salience. Thus, following AX-US trials, during A-US trials (i.e., the second phase of a backward-blocking treatment) CS A acquires further associative strength, whereas CS X loses its previously acquired associative strength. Similarly, in Dickinson and Burke's revision of Wagner's SOP model (hereafter, SOP-R), absent (but expected) CSs can also acquire an association (either excitatory or inhibitory) with the US, just as CSs that are present do, but of the opposite type (e.g., inhibitory, rather than excitatory).

In the framework of Dickinson and Burke's (1996) SOP-R model, backward blocking is explained as CSs $\mathrm{A}$ and $\mathrm{X}$ acquiring during the $\mathrm{AX}-\mathrm{US}$ trials, not only an association with the US, but also an association with each other (i.e., an $\mathrm{A}-\mathrm{X}$ association). When $\mathrm{A}$ is presented without $\mathrm{X}$ following the AX-US trials, the representation of CS X is activated by the A-X association into the socalled A2 memory state (see Wagner, 1981, for a detailed discussion). Contrary to Wagner's original SOP model, in which only CSs that are present (i.e., represented) in the A1 memory state could change their associative strength, in SOP-R CSs that are active in either A1 or A2 can update their associative strengths, but in opposite directions. Thus, in backward blocking, on each A-US trial given after AX-US trials, CS A and the US will be activated into A1, whereas CS X will be activated into A2. The concurrent activation of A and the US in A1 will strengthen the A-US association, whereas CS X will develop an inhibitory association with the US, due to the concurrent activation of $\mathrm{X}$ and the US in different states (i.e., A2 and A1, respectively). As a consequence of acquisition of this inhibitory X-US association, responding to CS X weakens (i.e., is backward blocked).

In Dickinson and Burke's (1996) SOP-R model, withincompound associations play a critical role in so-called retrospective revaluation effects (i.e., revaluation of the associative status of an absent target CS on the basis of new experiences with the target's associate), such as backward blocking and recovery from overshadowing (i.e., recovery of responding to $\mathrm{X}$, due to extinction of $\mathrm{A}$ following AX-US trials; see, e.g., Kaufman \& Bolles, 1981; Matzel, Schachtman, \& Miller, 1985; Wasserman \& Berglan, 1998). According to SOP-R, in forward blocking, CS X acquires a weak association with the US, due to the presence of CS A. Specifically, on each AX-US trial, the US will be activated into A2 and, to a lesser extent, into A1. First, during the presentation of the AX compound, CS A activates the US into A2, which results in learning of an inhibitory $\mathrm{X}-\mathrm{US}$ association, due to the concurrent activation of $\mathrm{X}$ and the US in A1 and A2, respectively. Then, when the US is presented, those elements of its representation that are not already in A2 can be activated in A1, so that $\mathrm{X}$ and the US can form a weak excitatory association, due to their being concurrently activated in A1. The ex- citatory and inhibitory X-US associations will counteract each other, resulting in the acquisition of a weak net excitatory associative strength (for a detailed discussion, see Larkin et al., 1998). Importantly, in this account of forward blocking, the association formed between A and $\mathrm{X}$ plays no role at all, whereas this association is critical for the occurrence of backward blocking.

In a different vein, Melchers, Lachnit, and Shanks (2004) supported Chapman's (1991) proposal that rehearsal processes might be involved in retrospective revaluation. In the framework of the rehearsal account, as in the aforementioned revised models (i.e., Dickinson \& Burke, 1996; Van Hamme \& Wasserman, 1994), withincompound associations are critical for the occurrence of retrospective revaluation. However, contrary to these revised models, the rehearsal account does not posit that retrospective revaluation is due to any special learning process involving a representation of the absent CS (i.e., a negative $\alpha$ in Van Hamme \& Wasserman's [1994] model and the A2 state in SOP-R), which is assumed to counteract the impact of the learning process involving the representation of a physically present CS (i.e., a positive $\alpha$ in Van Hamme \& Wasserman's [1994] model and the A1 state in SOP-R). Rather, according to the rehearsal view, in retrospective revaluation the presentation of CS A following training with the AX compound will retrieve (rehearse) the memory of the previous AX-US trials, which, in turn, will result in an updating of CS X's status as a function of whether CS A is further paired with the US (backward blocking) or presented alone (recovery from overshadowing). In this case, a competitive learning rule, such as that of Rescorla and Wagner (1972), could be applied to explain retrospective revaluation, assuming that the impact of rehearsing the AX-US trials during A-US (or A-no-US) trials is similar to that of a treatment with intermixed A-US (or A-alone) and AX-US trials. This treatment, similar to a single-phase blocking (or singlephase recovery from overshadowing), is predicted to be weaker than forward blocking (or forward recovery from overshadowing), according to associative models such as that of Rescorla and Wagner. Furthermore, the rehearsal process is not necessary in order to explain direct learning effects, such as forward blocking. If anything, rehearsing the A-US trials during AX-US trials could enhance blocking, but the occurrence of forward blocking is not assumed to depend on rehearsal. Therefore, the rehearsal account can explain not only why retrospective revaluation is usually found to be weaker than direct learning, but also evidence indicating that retrospective revaluation (but not direct learning) seems to depend on within-compound associations (e.g., Dickinson \& Burke, 1996; Larkin et al., 1998; Melchers et al., 2004).

In contrast to the preceding acquisition-focused accounts of blocking, Miller and Matzel's (1988; also see Miller \& Schachtman, 1985) comparator hypothesis assumes that the within-compound association is critical in both forward and backward blocking. Indeed, the comparator hypothesis does not formally distinguish between forward and backward blocking, because regardless of the 
order of training of the blocking and blocked associations, both effects are based on the impaired expression of the target association during testing. Specifically, according to the comparator hypothesis, both forward and backward blocking occur due to a comparison process initiated by the presentation of the target CS at test on the basis of the three different associations that are learned during training: the X-US association, the A-US association, and the $\mathrm{X}-\mathrm{A}$ within-compound association. The lower left panel of Figure 1 depicts this comparison process. First, the presentation of CS X during testing is assumed to directly activate a representation of the US through the X-US association (i.e., Link 1), as well as the representation of CS A (i.e., X's comparator stimulus) through the $\mathrm{X}-\mathrm{A}$ within-compound association (i.e., Link 2). In turn, the representation of CS A activates a representation of the US through the A-US association (i.e., Link 3). Therefore, CS X activates the US representation both directly (i.e., through Link 1) and indirectly (i.e., through Links 2 and 3). The strength of the direct activation of the US will be a function of the strength of Link 1 (i.e., the X-US association), whereas the strength of the indirect activation of the US will be a function of the product of the strengths of Links 2 and 3 (i.e., the $\mathrm{X}-\mathrm{A}$ and $\mathrm{A}-\mathrm{US}$ associations). The response strength is assumed to be the result of a comparison between the direct and the indirect activations of the US representation. When the direct activation of the US representation elicited by CS X is strong relative to the indirect activation of the US representation elicited by CS X (by mediation through CS A), a strong response to CS X will be observed. By contrast, when this relationship is reversed, weak or no responding will be observed. This is exactly what happens in both forward and backward blocking, according to the comparator hypothesis.

\section{Attenuation of Blocking by Extending Training of the Blocking Association: A Prediction of SOP-R and the Comparator Hypothesis}

Due to the important role given by Dickinson and Burke's (1996) SOP-R model and Miller and Matzel's (1988) comparator hypothesis to the $\mathrm{A}-\mathrm{X}$ within-compound association in their explanation of backward blocking, both models predict that any treatment that weakens the within-compound association should attenuate backward blocking. Although counterintuitive, one such treatment consists of extended training of the A-US blocking association, a treatment that at first could be expected to enhance, rather than attenuate, the backward-blocking effect. This occurs so because, on each A-US trial, CS A is presented in the absence of the target $\mathrm{CS}(\mathrm{X})$ and, hence, the $\mathrm{A}-\mathrm{X}$ within-compound association undergoes extinction. However, despite extended training of the blocking association being expected to produce, according to both SOP-R and the comparator hypothesis, extinction of the within-compound associa-

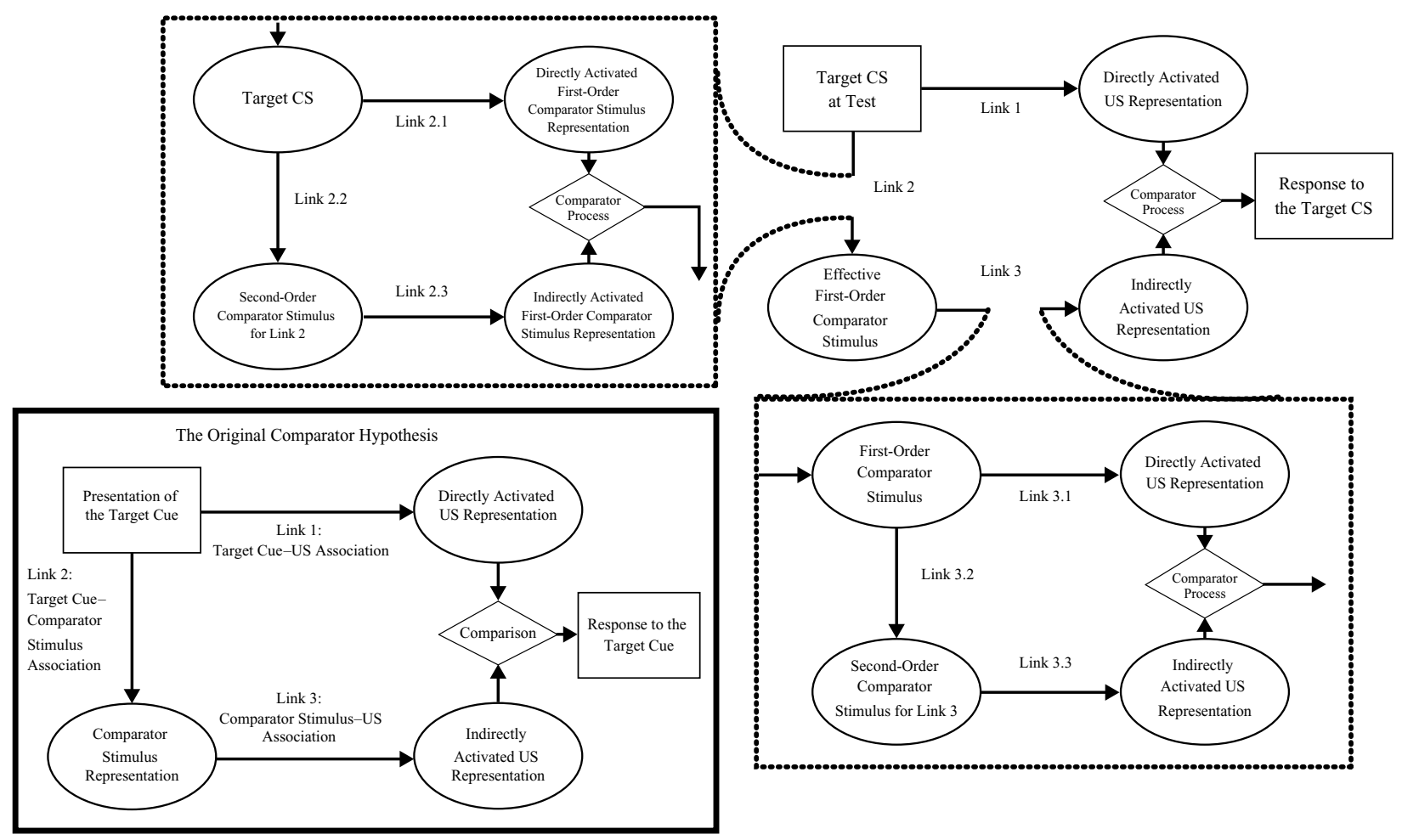

Figure 1. The lower left panel depicts the original comparator hypothesis (Miller \& Matzel, 1988). The remainder of the figure depicts the extended comparator hypothesis (Denniston, Savastano, \& Miller, 2001). Applied to extended training of the A-US association following compound training in the present research, the target conditioned stimulus (CS) is X; $\mathrm{A}$ is the effective first-order comparator stimulus, and the context is the effective second-order comparator stimulus for Link 3. 
tion, attenuation of backward blocking is predicted to take place, for completely different reasons, in each model. A detailed explanation of the processes involved in each model's prediction of attenuation of backward blocking by extended training of the blocking association will further clarify this point.

According to Dickinson and Burke's (1996) SOP-R model, extinction of the within-compound association produced by extensive training of the blocking association should result in a progressive decrease in the $\mathrm{A} 2$ activation of CS X's representation by CS A and, hence, in a weaker revaluation of the $\mathrm{X}-\mathrm{US}$ association. Thus, once the within-compound association is completely extinguished, the X-US association will not be further revalued (i.e., $\mathrm{X}$ will not accrue additional inhibitory strength, despite further A-US trials). However, the revaluation previously undergone by the X-US association will remain intact; that is, extinction of the $\mathrm{A}-\mathrm{X}$ within-compound association will impair CS A's potential to further revaluate the $\mathrm{X}$-US association in subsequent trials, but CS X will remain blocked, despite the weakened status of the $\mathrm{A}-\mathrm{X}$ within-compound association.

At first, it could be thought that with no additional assumption, Dickinson and Burke's (1996) SOP-R model therefore predicts that extended A-US pairings following the compound trials should produce, if anything, stronger blocking of the $\mathrm{X}-\mathrm{US}$ association. However, a discussion of the SOP-R model based only on the dynamics of the A2 activation of CS X (which strictly follows Dickinson and Burke's original formulation of the model) is too simplistic. As has been proposed by Larkin et al. (1998), on each successive A-US trial in a backward-blocking treatment, CS A activates into the A2 state not only CS X, but also the US. Hence, one could assume that as extended A-US trials proceed to strengthen the excitatory A-US association, CS A more strongly activates the US into the A2 state. This stronger A2 activation of the US, conjointly with the A2 activation of X (also elicited by CS A), could result in a strengthening of the excitatory X-US association. Moreover, the stronger A2 activation of the US over increasing numbers of $\mathrm{A} \rightarrow \mathrm{US}$ presentations should impair the subsequent activation of the US into A1 during its own presentation, thereby attenuating the formation of an inhibitory X-US association. Although the A2 activation of CS X would be predicted to weaken on each successive A-US trial, due to extinction of the A-X excitatory association, the possibility of X's forming an excitatory association with the US during extended A-US trials following the compound trials remains viable. In order for the excitatory X-US association to be strengthened during the A-US pairings after compound training, the SOP-R model would merely need to assume that extinction of the A-X association proceeds more slowly than the strengthening of the A-US association and, with it, the corresponding strengthening of the X-US association.

To summarize, SOP-R assumes that extending training of the blocking association following compound training not only can extinguish the A-X within-compound association, but also can attenuate backward blocking. But im- portantly, the predicted attenuation of backward blocking is not due to extinction of the within-compound association (i.e., these two consequences of extended training of the blocking association are assumed to be independent). Rather, attenuated blocking is expected in the framework of SOP-R, due to the acquisition of an excitatory association between the representations of CS X and the US, both of them activated into A2 by CS A. Although withincompound associations play a critical role in backward, but not forward, blocking according to SOP-R, extended training of the A-US association following compound training might be expected to attenuate both forward and backward blocking.

According to the comparator hypothesis (Miller \& Matzel, 1988), extended training of the blocking association should also attenuate both forward and backward blocking. However, contrary to SOP-R, in the framework of the comparator hypothesis extinction of the within-compound association itself, instead of any putative additional process (i.e., acquisition of an excitatory association between the absent stimuli, $\mathrm{X}$ and $\mathrm{O}$, associatively activated by $\mathrm{CS}$ A over extended $\mathrm{A}-\mathrm{O}$ pairings), is directly responsible for the attenuation of forward and backward blocking. This is because the comparator hypothesis assumes that the within-compound association, which plays a critical role in all CS competition effects, including both forward and backward blocking, must be functional at the time of testing in order for blocking to be observed (as opposed to SOP-R, which assumes that the within-compound association must be functional during training). Therefore, the comparator hypothesis predicts that extinction of the A-X within-compound association achieved by extended training of the A-US association will attenuate blocking. Specifically, extinction of the $\mathrm{X}-\mathrm{A}$ association (Link 2 in the small panel of Figure 1) should attenuate the activation of CS A during testing of X, thereby reducing competition by the A-US association with the expression of the $\mathrm{X}$-US association.

\section{A Third Possible Mechanism Producing Attenuation of Blocking by Extending Training of the Blocking Association: \\ Extended Comparator Processes}

The prediction by the comparator hypothesis of attenuation of blocking as a consequence of extended A-US pairings after the AX-US trials is shared by the recent extension of this model by Denniston, Savastano, and Miller (2001). In the extended comparator hypothesis, as in the original comparator hypothesis, the presentation of the target CS at test activates the US representation both directly (Link 1) and indirectly (Links 2 and 3). The main part of Figure 1 depicts the extended comparator hypothesis. As can be seen, in both the original and the extended comparator hypotheses, a companion CS (A) can impair or down-modulate responding to a target CS (X). The only important difference between the original and the extended comparator hypotheses is that CS A's own comparator stimuli can also have an effect on responding to X. Specifically, the first-order comparator stimuli of CS A will play the role of X's second- 
order comparator stimuli, thereby down-modulating A's potential as a down-modulator of responding to $\mathrm{X}$. Thus, whereas changes in the associative status of a first-order comparator stimulus result in inverse changes in responding to the target CS X, the model predicts that changes in the associative status of a second-order comparator stimulus should result in similar changes in responding to the target CS X. Consequently, the extended comparator hypothesis, like its predecessor, predicts that extended training of the blocking association will attenuate blocking, due to extinction of Link 2 during A-US trials.

Importantly, the extended comparator hypothesis also makes this same prediction on the basis of a second mechanism, as well as that stated above. In the framework of the extended comparator hypothesis, the blocking effect might be attenuated, due to the context's becoming a strong excitatory second-order comparator for the target CS. Specifically, according to the extended comparator hypothesis, during extensive A-US trials the context forms a strong association with both CS A (i.e., Link 3.2) and the US (i.e., Link 3.3) and, thus, becomes an effective comparator stimulus for the A-US association (Link 3.1).
Figure 2 depicts the extended comparator hypothesis as applied to this situation - that is, the second-order comparison process in which extensive A-US trials following few AX-US trials cause the context-US association to down-modulate the A-US association. As can be seen in this figure, the role of the context as a second-order comparator stimulus is assumed to primarily down-modulate Link 3.1 (A-US association) because of the many A-US trials, whereas the context's role as a second-order comparator with respect to Link 2.1 (X-A association) is assumed to be negligible, given a small number of AX-US trials (i.e., a relatively weak $\mathrm{X}$-context association). Because the context-US association directly down-modulates expression of the A-US association, and because the A-US association directly down-modulates expression of the X-US association, the context-US association will indirectly enhance or up-modulate the expression of the X-US association and, thus, will release CS X from blocking.

Some clarifications of this prediction by the extended comparator hypothesis concerning the impact of extended A-US pairings after AX-US compound training are necessary. Here, we have suggested that CS A becomes a

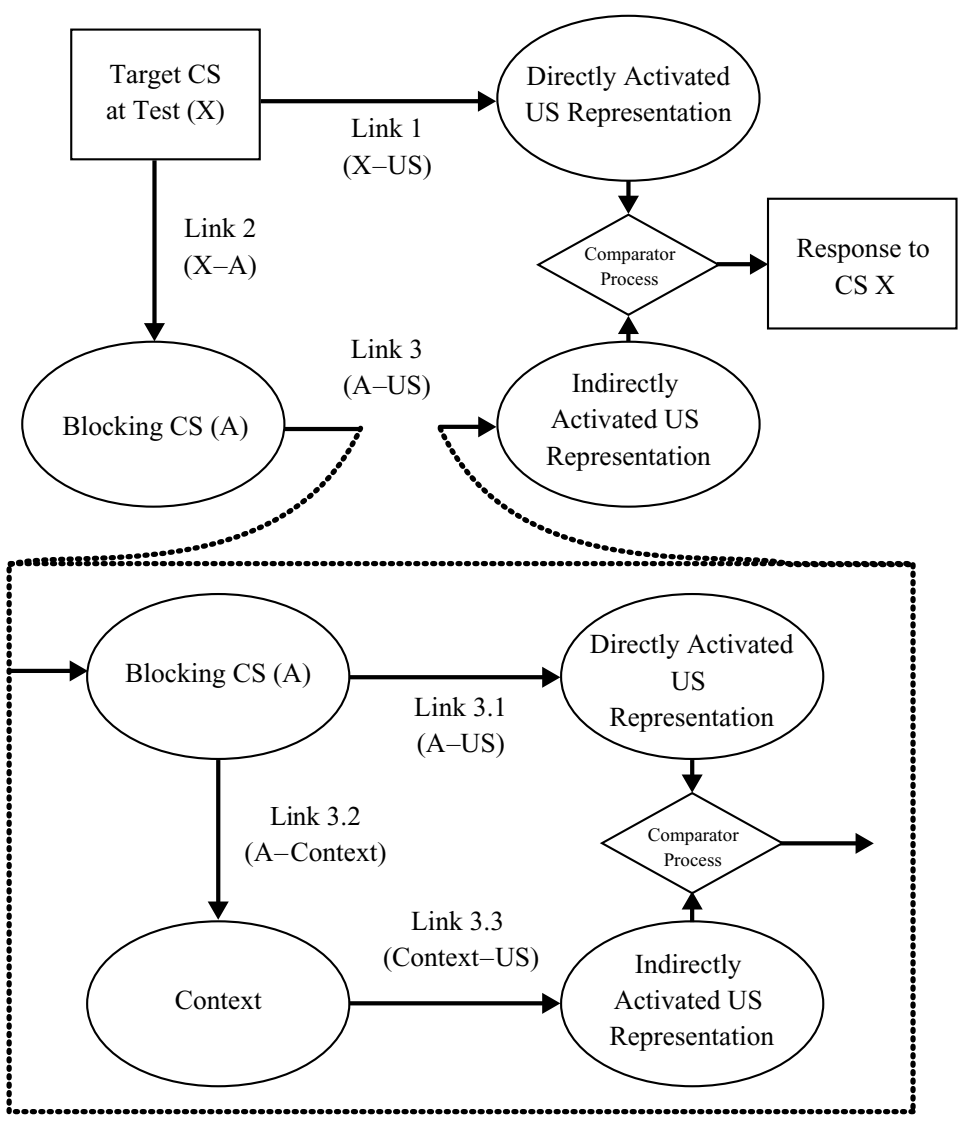

Figure 2. Extended comparator hypothesis (Denniston, Savastano, \& Miller, 2001), applied to extended training of the A-US association following compound training in the present research. The target conditioned stimulus (CS) is $\mathrm{X} ; \mathrm{A}$ is the effective first-order comparator stimulus, and the context is the effective second-order comparator stimulus for Link 3 . The higher order comparator effect on Link $\mathbf{2}$ is omitted because it is negligible in this situation. 
first-order comparator stimulus for CS X, whereas the context becomes a first-order comparator stimulus for CS A and, hence, a second-order comparator stimulus for CS X. However, it could be asked why the context is not assumed to play the role of a first-order comparator stimulus not only of CS A, but also of CS X. The reason for this is the same one previously pointed out regarding the negligible role of the context as a second-order comparator for Link 2.1. The context could be a first-order comparator stimulus for CS X, just as CS A is, because $\mathrm{X}$ is paired with the US in the presence of both CS A and the context during the AX-US trials. However, the context is expected to become, if anything, a very weak first-order comparator stimulus for CS X, due to (1) the small number of AX-US trials that are usually given in a backward-blocking design (in our present experiments, 4 trials), (2) the weak salience of contextual stimuli, relative to that of a punctate CS such as A, and (3) a potential extinction of the X-context association on the basis of extensive exposure to contextual stimuli in the absence of X. By contrast, the context might become a strong first-order comparator stimulus for CS A because of its extensive pairings with the US (in our present experiments, 200 trials). ${ }^{1}$

Another question that might be asked is why CS A and the context are, in this extended comparator hypothesis account, first-order and second-order comparator stimuli for CS X, respectively, instead of the context being the first-order comparator stimulus and CS A being the second-order comparator stimulus. This assignation of the roles of first-order and second-order comparator stimuli to CS A and the context is not arbitrary. Rather, it is based on the expected strength of the different associations at the time of testing, as well as on which stimulus is presented at test. In the present case (i.e., backward blocking with extended A-US trials), the representation of CS A is assumed to be directly activated by the physically present CS X on the basis of a relatively strong $\mathrm{X}-\mathrm{A}$ association (in comparison with the $\mathrm{X}$-context association) formed during the AX-US trials. In turn, the activation of CS A's representation presumably activates the representation of the context, on the basis of the A-context association formed during the extended A-US trials. Therefore, the physical presentation of one or another CS at test determines the roles of the different associates as either first-order or second-order comparator stimuli. If CS A, instead of CS X, was presented at test, both CS X and the context would be significant first-order comparator stimuli of CS A, due to their strong, direct associations with CS A. As a consequence of this, and contrary to the predictions regarding testing with CS X (i.e., recovery of responding), extended training of the A-US association is expected to result in a weakening of the response elicited by CS A at test.

Finally, it is important to note that these alternative mechanisms leading to a prediction of attenuation of blocking in the original and extended comparator hypotheses are, to some extent, incompatible. The second-order comparator process effectively weakening Link 3.1 (extended comparator hypothesis only) requires the presence of the $\mathrm{X}-\mathrm{A}$ within-compound association to mediate be- tween the context and X, whereas the weakening of Link 2 reflects the extinction of the within-compound association (both the original comparator hypothesis and the extended version).

\section{Overview of the Experiments}

To summarize the previous discussion, on the basis of very different mechanisms, Dickinson and Burke's (1996) SOP-R model, the comparator hypothesis (Miller \& Matzel, 1988), and the extension of the comparator hypothesis (Denniston et al., 2001) predict that extended pairings of the blocking CS with the US after the compound trials will recover responding to the blocked CS. That is, these models counterintuitively predict that in associative-learning phenomena, more can be less: More training of the blocking association following compound training can reduce the blocking effect. Experiments 1 and 2 assessed this prediction, with no attempt to discriminate between the accounts of the aforementioned theories, by studying the impact of extended training of the blocking association on backward blocking (Experiment 1) and forward blocking (Experiment 2). Experiment 3 replicated and extended Experiment 1 to directly contrast the explanations offered by SOP-R, the comparator hypothesis, and the extended comparator hypothesis.

\section{EXPERIMENT 1}

Experiment 1 assessed whether backward blocking could be attenuated by extended training of the blocking association. Backward-blocking treatment was embedded within a sensory preconditioning, because previous studies from our laboratory (e.g., Denniston, Miller, \& Matute, 1996; Miller \& Matute, 1996a, 1996b) had shown that backward blocking is difficult to obtain in a firstorder conditioning preparation, which is a result that we attribute to CS X's becoming biologically significant in Phase 1 (i.e., during AX-US trials). Therefore, instead of directly pairing CSs X and A with the US during training, we paired these CSs with a surrogate outcome $(\mathrm{O})$ consisting of a neutral stimulus. This surrogate outcome was paired with the footshock US after the AX-O and A-O pairings had occurred.

The design of Experiment 1 is summarized in Table 1. Four groups of subjects were given compound presentations of CSs $\mathrm{A}$ and $\mathrm{X}$, followed by $\mathrm{O}$ (i.e., $\mathrm{AX}-\mathrm{O}$ trials). In the Backward-Blocking (BB) condition, the subjects received additional $\mathrm{A}-\mathrm{O}$ pairings, whereas in the Control condition the subjects received presentations of a different CS (B), followed by O (i.e., B-O trials). Moreover, during Phase 2, subjects in condition Few received moderate training of either the $\mathrm{A}-\mathrm{O}$ association (i.e., group BB-Few) or the $\mathrm{B}-\mathrm{O}$ association (i.e., group Control-Few), whereas in condition Many, the subjects received extensive training of either the $\mathrm{A}-\mathrm{O}$ association (i.e., group BB-Many) or the $\mathrm{B}-\mathrm{O}$ association (i.e., group Control-Many). Then, in Phase 3 all the groups were given pairings of $O$ with the US (i.e., O-US trials), in order to make $\mathrm{O}$ a first-order CS and allow assessment of the $\mathrm{X}-\mathrm{O}$ association. Finally, all 
Table 1 Design of Experiment 1

\begin{tabular}{lcccc}
\hline \multicolumn{1}{c}{ Group } & Phase 1 & Phase 2 & Phase 3 & Test \\
\hline BB-Few & $4 \mathrm{AX} \rightarrow \mathrm{O}$ & $20 \mathrm{~A} \rightarrow \mathrm{O}$ & $4 \mathrm{O} \rightarrow \mathrm{US}$ & $1 \mathrm{X}$ \\
Control-Few & $4 \mathrm{AX} \rightarrow \mathrm{O}$ & $20 \mathrm{~B} \rightarrow \mathrm{O}$ & $4 \mathrm{O} \rightarrow \mathrm{US}$ & $1 \mathrm{X}$ \\
BB-Many & $4 \mathrm{AX} \rightarrow \mathrm{O}$ & $200 \mathrm{~A} \rightarrow \mathrm{O}$ & $4 \mathrm{O} \rightarrow \mathrm{US}$ & $1 \mathrm{X}$ \\
Control-Many & $4 \mathrm{AX} \rightarrow \mathrm{O}$ & $200 \mathrm{~B} \rightarrow \mathrm{O}$ & $4 \mathrm{O} \rightarrow \mathrm{US}$ & $1 \mathrm{X}$ \\
\hline
\end{tabular}

Note-BB, backward blocking; $\mathrm{A}$ and $\mathrm{B}$, complex tone and white noise, counterbalanced; X, click train; O, flashing light; US, footshock. The numbers denote the number of presentations of each trial type in each phase.

the groups were tested on $\mathrm{X}$. In this experiment, a weaker response to CS X in condition BB-Few than in condition Control-Few would be indicative of backward blocking. More important, if extended training of the blocking CS (A) produces an attenuation of blocking, as predicted by SOP-R, as well as by the original and the extended comparator hypotheses, stronger responding to CS X should be observed in group BB-Many than in group BB-Few.

\section{Method}

\section{Subjects}

The subjects were 24 male (353-415 g) and 24 female (190$280 \mathrm{~g}$ ) Sprague Dawley, experimentally naive, young adult rats, bred in our colony. The subjects were individually housed and maintained on a 16:8-h light:dark cycle, and experimental sessions occurred roughly midway through the light portion. Prior to initiation of the experiment, water availability was progressively reduced to $30 \mathrm{~min}$ per day and, during the experiment, was provided approximately $2 \mathrm{~h}$ after any scheduled treatment. The subjects had free access to food in the home cage. From weaning to the initiation of the experiment, all the subjects were handled for $30 \mathrm{sec}$ three times a week.

\footnotetext{
Apparatus

The apparatus consisted of 12 identical chambers, each measuring $30 \times 25 \times 32 \mathrm{~cm}(1 \times \mathrm{w} \times \mathrm{h})$. The walls of each chamber were made of Plexiglas, and the floor was constructed of 0.5 -cm-diameter rods, spaced $2 \mathrm{~cm}$ center to center and connected by NE- 2 neon bulbs that allowed a $0.675-\mathrm{mA}$ constant-current footshock to be delivered by means of a high-voltage $\mathrm{AC}$ circuit in series with a $1.0-\mathrm{M} \Omega$ resistor. Each chamber was housed in an environmental isolation chest, which was dimly illuminated by a houselight (No. 1820 incandescent bulb) mounted on the ceiling of the experimental chamber. Each chamber was equipped with a water-filled lick tube (opening, $0.3 \mathrm{~cm}$ in diameter) that extended $1 \mathrm{~cm}$ from the rear of a cylindrical niche, $4.5 \mathrm{~cm}$ in diameter, which was left-right centered on one wall, with its axis perpendicular to the wall and positioned $4 \mathrm{~cm}$ above the grid floor. An infrared photobeam was projected horizontally across the niche, $1 \mathrm{~cm}$ in front of the lick tube. In order to drink from the tube, the subjects had to insert their heads into the niche, thereby breaking the infrared photobeam. The amount of time the photobeam was disrupted served as our dependent measure. A $45-\Omega$ speaker mounted on the interior back side of each environmental chest was used to deliver a high-frequency complex tone stimulus (a blend of 3000 and $3200 \mathrm{~Hz}$ ), $8 \mathrm{~dB}$ above background. A second $45-\Omega$ speaker mounted on the ceiling of the experimental chamber was used to deliver a click stimulus $(6 / \mathrm{sec}) 8 \mathrm{~dB}$ above background. A third $45-\Omega$ speaker mounted on a sidewall of the chamber was used to deliver a white noise stimulus $8 \mathrm{~dB}$ above background. Ventilation fans in each enclosure provided a constant $72-\mathrm{dB}$ background noise. All the auditory cues were measured on the $\mathrm{C}$ scale. A $150-\mathrm{W}$ bulb (nominal at $120 \mathrm{VAC}$, driven at $90 \mathrm{VAC}$ ) mounted on the interior back of the environmental chest was used to deliver a flashing light $(0.5 \mathrm{sec}$ on $/ 0.5 \mathrm{sec}$ off).
}

\section{Procedure}

The subjects were randomly assigned to one of four groups (BBFew, Control-Few, BB-Many, Control-Many), counterbalanced for sex $(n \mathrm{~s}=12)$. CS X was always the click train. CSs A and B were the complex tone and the white noise, counterbalanced within groups. $\mathrm{O}$ consisted of the presentation of the flashing light together with the houselight turned off. The US was a $0.5-\mathrm{sec}, 0.675-\mathrm{mA}$ footshock. When presented during training, all CSs and O were $5 \mathrm{sec}$ in duration. On all the trials in which $\mathrm{O}$ was presented, the onset of $\mathrm{O}$ coincided with the termination of the CS. During first-order conditioning, the onset of the US coincided with the termination of O.

The sessions differed in duration, depending on the number of trials that were given within each session. Those training sessions in which 4 trials were given were $60 \mathrm{~min}$ in duration, and the CS presentations occurred at 9,30,38, and 53 min into each session; whereas those training sessions in which 20 trials were given were $75 \mathrm{~min}$ in duration, and the CS presentations took place at $3,7,10$, $13,17,20,26,30,33,38,41,45,49,52,57,60,64,68,70$, and 73 min into each session.

Acclimation. On Day 1, all the subjects were acclimated to the experimental context for $60 \mathrm{~min}$ with the lick tubes present. No nominal stimuli were presented during this session. At the end of this session, the lick tubes were removed.

Phase 1. On Day 2, all the groups received four AX-O pairings in a single session.

Phase 2. Days 3-12 consisted of one session per day. On Days 3-11, group BB-Many received $20 \mathrm{~A}-\mathrm{O}$ pairings, and group Control-Many received $20 \mathrm{~B}-\mathrm{O}$ pairings. On these sessions, the animals in groups BB-Few and Control-Few were handled in the same fashion as the animals in condition Many but received no nominal stimulus presentation or exposure to the experimental context. On Day 12, groups BB-Few and BB-Many received $20 \mathrm{~A}-\mathrm{O}$ pairings, whereas groups Control-Few and Control-Many received $20 \mathrm{~B}-\mathrm{O}$ pairings.

Phase 3. On Day 13, all groups received four O-US pairings.

Reacclimation. On Days 14 and 15, all the groups were reacclimated to the experimental context during daily 60-min sessions. During reacclimation, the lick tubes were returned to the chambers, and no nominal stimuli were presented. These sessions served to restabilize baseline drinking following any potential disruption produced by the footshock USs.

Testing. On Day 16, all the groups were tested for conditioned lick suppression to X. During this session, the subjects were allowed to drink from the lick tubes for 5 cumulative seconds in the absence of any CS. Following this initial period of drinking, the target CS (X) was presented. Thus, all the animals were drinking at CS onset. Both the time to complete 5 cumulative seconds of licking in the absence of the CS (pre-CS time) and in the presence of the CS (CS time) were recorded. A $900-\mathrm{sec}$ ceiling was imposed on all the suppression scores. Following the established practice of our laboratory, the data from all the subjects that took longer than $60 \mathrm{sec}$ to complete 5 cumulative seconds of drinking prior to the onset of the CS were eliminated from the analysis, because such long latencies presumably reflected unusual fear of the context. Four subjects (i.e., 1 from group BB-Few and 3 from group Control-Few) met this criterion in the present experiment. Our dependent measure was time to complete 5 cumulative seconds of drinking in the presence of the test stimulus. Prior to statistical analysis, all the suppression scores were converted to $\log$ (base 10) scores to better approximate within-group normal distributions of scores, as required for the use of parametric statistical analysis. An alpha level of $p<.05$ was adopted for all the statistical analyses.

\section{Results and Discussion}

The results of Experiment 1 are depicted in Figure 3. As can be appreciated from this figure, group BB-Few exhibited weaker conditioned suppression than did group Control-Few, suggesting that backward blocking oc- 
curred in condition Few. More important, conditioned suppression to $\mathrm{X}$ was strong in both groups BB-Many and Control-Many, indicating attenuation of backward blocking in condition Many.

A 2 (condition: BB vs. Control) $\times 2$ (posttraining trials: Few vs. Many) ANOVA on the baseline scores (i.e., times to complete 5 cumulative seconds of drinking prior to CS onset) showed no main effect or interaction (all $p \mathrm{~s}>.20$ ). Despite having found no difference in the pre-CS scores, for the sake of consistency with analyses of the other experiments in this series, the subsequent analysis of the suppression scores at test in Experiment 1 also included the pre-CS scores as a covariate. (Notably, the results of the present experiments were not dependent on the inclusion of the pre-CS scores as a covariate; identical results were obtained when analogous ANOVAs that did not include the pre-CS scores as a covariate were performed.)

A 2 (condition: BB vs. Control) $\times 2$ (posttraining trials: Few vs. Many) ANCOVA on the suppression scores in the presence of CS X during testing, using the pre-CS scores as a covariate, yielded main effects of condition $\left[F(1,39)=19.13, M S_{\mathrm{e}}=0.21, p<.01\right]$ and posttraining trials $\left[F(1,39)=10.29, M S_{\mathrm{e}}=0.21, p<.01\right]$. More important, this ANCOVA also detected a condition $\times$ posttraining trials interaction $\left[F(1,39)=12.27, M S_{\mathrm{e}}=0.21\right.$, $p<.01]$. Planned comparisons using the overall error term from the ANCOVA revealed that conditioned suppression to CS X was weaker in group BB-Few than in group Control-Few $[F(1,39)=27.84, p<.01]$, but not in group BB-Many in comparison with group Control-Many $(p>$ $.54)$. Also, conditioned suppression was weaker in group BB-Few than in group BB-Many $[F(1,39)=23.75, p<$ $.01]$.

The results of Experiment 1, therefore, provide evidence of backward blocking in a conditioned lick suppression preparation after moderate training of the blocking association (i.e., groups BB-Few vs. Control-Few). More important, this experiment also demonstrated that conditioned responding elicited by the backward-blocked CS can be recovered by extended training of the blocking association (i.e., groups BB-Many vs. Control-Many). These observations are compatible with the predictions of SOP-R, as well as with both the original and the extended comparator hypotheses (see the introduction for a detailed discussion). The results of Experiment 1 also revealed that extensive presentations of $\mathrm{O}$ in condition Many did not produce latent inhibition of the $\mathrm{O}-\mathrm{US}$ association, as was shown by strong responding during testing on $\mathrm{X}$ in this condition. Possibly, the presentation of a punctate CS prior to $\mathrm{O}$ prevented the occurrence of latent inhibition. Although extended $\mathrm{A}-\mathrm{O}$ pairings did not produce latent inhibition of $\mathrm{O}$, this treatment might have resulted in the context's forming an association with both $\mathrm{CS} \mathrm{A}$ and $\mathrm{O}$, thereby becoming a first-order comparator stimulus for the A-O association. In this case, the context should not equally down-modulate the expression of all associations involving $\mathrm{O}$. That is, the context might have down-modulated the $\mathrm{X}-\mathrm{O}$ association on the basis of the four AX-O trials, but due to the extended training of the $\mathrm{A}-\mathrm{O}$ association, the context would be expected to have become a relatively much stronger first-order comparator for the latter association. In fact, this is the explanation provided by the extended comparator hypothesis on attenuation of blocking achieved by extended training of the blocking association. Experiment 2 was performed to assess these assumptions.

\section{EXPERIMENT 2}

The observed attenuation of backward blocking achieved by extensively training the blocking CS (A) after AX-O trials in Experiment 1 is consistent with the predictions of SOP-R and both the original and the extended comparator hypotheses. Experiment 2 studied whether extensively training the $\mathrm{A}-\mathrm{O}$ association following forward blocking can also recover responding to the blocked CS (X). Experiment 2 used a design similar to that in Blaisdell,

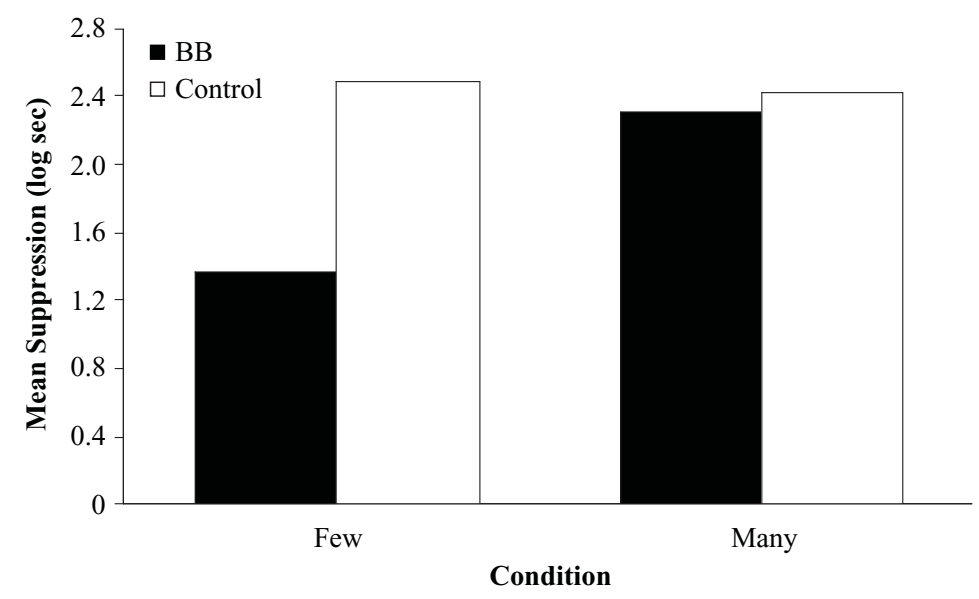

Figure 3. Results of Experiment 1: ANCOVA adjusted mean times to complete 5 cumulative seconds of drinking in the presence of CS X. BB, backwardblocking group. 
Gunther, and Miller (1999; see also Arcediano, Escobar, \& Matute, 2001), in which, following forward-blocking treatment, nonreinforced presentations (i.e., extinction) of the blocking CS were given in order to recover responding to the blocked CS. However, contrary to Blaisdell et al.'s experiments, in the present experiment, the subjects received additional reinforced presentations of the blocking CS following the forward-blocking treatment.

Demonstrating that extensive $\mathrm{A}-\mathrm{O}$ trials given after the compound trials can produce response recovery not only after backward blocking (Experiment 1) but also after forward blocking would provide further support for the predictions of the previously discussed models (i.e., SOP-R and the original and extended comparator hypotheses), something desirable given the novelty of the findings of Experiment 1. Also, the design of Experiment 2 further refined the design of Experiment 1, thereby allowing us to assess any interpretation of these findings based on differential latent inhibition of $\mathrm{O}$ (as well as any other effect due to differential exposure to $\mathrm{O}$ ) across groups.

The design of Experiment 2 is summarized in Table 2. In this experiment, all the groups received pairings of the compound $\mathrm{AX}$ with $\mathrm{O}$ during Phase 2. Prior to these AX-O trials, the subjects in condition Forward Blocking (FB) were given moderate training of the $\mathrm{A}-\mathrm{O}$ association in Phase 1, whereas the subjects in condition Control (Con) received B-O trials. Orthogonally, during Phase 3, the subjects in condition Backward Blocking (BB) were given extended training of the $\mathrm{A}-\mathrm{O}$ association, whereas the subjects in condition Control (Con) received extensive training of the $\mathrm{B}-\mathrm{O}$ association. Therefore, in this experiment, the observation of weaker suppression to CS X in group FB-Con than in group Con-Con would be indicative of forward blocking, whereas strong suppression in groups FB-BB and Con-BB and, more important, stronger suppression in group FB-BB than in group FB-Con would indicate that responding to the forward-blocked $\mathrm{CS}(\mathrm{X})$ was recovered by extensive $\mathrm{A}-\mathrm{O}$ pairings after the compound trials. Differences in responding to CS X at test could not be due to $\mathrm{O}$ being differentially subject to latent inhibition in different groups, because, contrary to Experiment 1, in Experiment 2 exposure to $\mathrm{O}$ was equated across groups. Rather, responding to CS X could be influenced only by the specific CS (A or B) that was paired with O during Phases 1 and 3.

In Experiment 2, we also tried to differentiate whether attenuation of blocking was due to the context's becoming a second-order comparator for CS X (as predicted by the extended comparator hypothesis) or to extinction of the A-X within-compound association (as predicted by both the original and the extended comparator hypotheses). Because the former account assumes that the context becomes a first-order comparator for CS A during extended training of the $\mathrm{A}-\mathrm{O}$ association, testing with this $\mathrm{CS}$ is theoretically relevant. Therefore, unlike in Experiment 1, we also tested CS A. If responding to CS A was weakened as a function of the number of $\mathrm{A}-\mathrm{O}$ trials, the conditioning of the context could potentially be responsible for the attenuation of blocking observed after extended training of the blocking association.

\section{Method \\ Subjects and Apparatus}

The subjects were 24 male (201-302 g) and 24 female (163223 g) Sprague Dawley, experimentally naive, young adult rats, bred in our colony. The subjects were maintained and housed as before. The apparatus was the same as that in Experiment 1.

\section{Procedure}

Unless mentioned, the procedural aspects of Experiment 2 were identical to those in Experiment 1.

Acclimation. On Day 1, acclimation proceeded exactly as in Experiment 1.

Phase 1. On Day 2, groups FB-BB and FB-Con received $20 \mathrm{~A}-\mathrm{O}$ pairings, whereas groups Con-BB and Con-Con received $20 \mathrm{~B}-\mathrm{O}$ pairings.

Phase 2. On Day 3, all the groups received four $\mathrm{AX}-\mathrm{O}$ pairings.

Phase 3. On Days 4-13, groups FB-BB and Con-BB received $20 \mathrm{~A}-\mathrm{O}$ pairings per day, whereas groups $\mathrm{FB}-\mathrm{Con}$ and $\mathrm{Con}-\mathrm{Con}$ received $20 \mathrm{~B}-\mathrm{O}$ pairings per day.

Phase 4. On Day 14, all the groups received four O-US pairings. Reacclimation. On Days 15 and 16, reacclimation proceeded as in Experiment 1.

Testing. On Days 17 and 18, all the groups were tested for conditioned lick suppression to X (Day 17) and A (Day 18). The test sessions proceeded identically to those in Experiment 1 . In this experiment, no subject took longer than $60 \mathrm{sec}$ to complete the first 5 cumulative seconds of drinking prior to the CS presentation on either test.

\section{Results and Discussion}

Figure 4 shows the results of Experiment 2. The left panel of Figure 4 shows the results of testing on X. As can be seen, forward blocking occurred when the control CS (B), instead of the blocking CS (A), was paired with $\mathrm{O}$ following training of the AX compound (i.e., group FB-Con vs. group Con-Con). However, when CS A was extensively

Table 2

Design of Experiment 2

\begin{tabular}{lccccc}
\hline Group & Phase 1 & Phase 2 & Phase 3 & Phase 4 & Test \\
\hline FB-BB & $20 \mathrm{~A} \rightarrow \mathrm{O}$ & $4 \mathrm{AX} \rightarrow \mathrm{O}$ & $200 \mathrm{~A} \rightarrow \mathrm{O}$ & $4 \mathrm{O} \rightarrow \mathrm{US}$ & $1 \mathrm{X}, 1 \mathrm{~A}$ \\
FB-Con & $20 \mathrm{~A} \rightarrow \mathrm{O}$ & $4 \mathrm{AX} \rightarrow \mathrm{O}$ & $200 \mathrm{~B} \rightarrow \mathrm{O}$ & $4 \mathrm{O} \rightarrow \mathrm{US}$ & $1 \mathrm{X}, 1 \mathrm{~A}$ \\
Con-BB & $20 \mathrm{~B} \rightarrow \mathrm{O}$ & $4 \mathrm{AX} \rightarrow \mathrm{O}$ & $200 \mathrm{~A} \rightarrow \mathrm{O}$ & $4 \mathrm{O} \rightarrow \mathrm{US}$ & $1 \mathrm{X}, 1 \mathrm{~A}$ \\
Con-Con & $20 \mathrm{~B} \rightarrow \mathrm{O}$ & $4 \mathrm{AX} \rightarrow \mathrm{O}$ & $200 \mathrm{~B} \rightarrow \mathrm{O}$ & $4 \mathrm{O} \rightarrow \mathrm{US}$ & $1 \mathrm{X}, 1 \mathrm{~A}$ \\
\hline
\end{tabular}

Note-FB, forward blocking; BB, backward blocking; Con, control treatment; $\mathrm{A}$ and $\mathrm{B}$, complex tone and white noise, counterbalanced; $\mathrm{X}$, click train; $\mathrm{O}$, flashing light; US, footshock. The numbers denote the number of presentations of each trial type in each phase. 
trained following $\mathrm{AX}-\mathrm{O}$ training, forward blocking was not observed (i.e., group FB-BB vs. group Con-BB). Moreover, extended training of the blocking association apparently recovered responding to the forward-blocked CS (i.e., group FB-Con vs. group FB-BB). The results of testing on A (see the right panel in Figure 4) suggest that conditioned suppression to A was weaker when this CS was extensively paired with $\mathrm{O}$ (i.e., groups $\mathrm{FB}-\mathrm{BB}$ and $\mathrm{Con}-\mathrm{BB}$ ) than when the control CS (B) was extensively paired with $\mathrm{O}$ (i.e., groups FB-Con and Con-Con). All these impressions were confirmed by the following analyses.

Two preliminary ANOVAs were performed in order to examine whether the pre-CS times differed among groups either during the test of $\mathrm{X}$ or during the test of A. A 2 (precompound treatment: FB vs. Con) $\times 2$ (postcompound treatment: BB vs. Con) ANOVA on baseline scores (i.e., times to complete 5 cumulative seconds of drinking prior to CS onset) showed no main effect or interaction (all $p \mathrm{~s}>$ .44). An identical ANOVA on the mean latencies in the pre-CS A period also showed no main effect or interaction (all $p \mathrm{~s}>$.18). Despite having found no difference in the pre-CS scores, for the sake of consistency with the analyses of the other experiments in this series, the subsequent analyses on the suppression scores at test in Experiment 2 also included pre-CS scores as a covariate.

A 2 (precompound treatment: FB vs. Con) $\times 2$ (postcompound treatment: BB vs. Con) ANCOVA on the suppression scores in the presence of CS X during testing, using the pre-CS scores as a covariate, yielded main effects of precompound treatment $\left[F(1,43)=17.81, M S_{\mathrm{e}}=\right.$ $0.19, p<.01]$ and postcompound treatment $[F(1,43)=$ $\left.7.49, M S_{\mathrm{e}}=0.19, p<.05\right]$, as well as an interaction $\left[F(1,43)=14.36, M S_{\mathrm{e}}=0.19, p<.01\right]$. Planned comparisons showed that conditioned suppression was weaker in group FB-Con than in group Con-Con $[F(1,43)=31.95$, $p<.01]$, thereby demonstrating that forward blocking was observed when CS B, instead of CS A, underwent extensive pairings with $\mathrm{O}$ after the compound trials. However, when the blocking CS was extensively trained after AX-O pairings, forward blocking was not observed, as is indicated by the similar conditioned suppression observed in groups FB-BB and Con-BB $(p>$.77). Finally, conditioned suppression was stronger in group $\mathrm{FB}-\mathrm{Con}$ than in group FB-BB $[F(1,43)=21.06, p<.01]$, showing that following forward-blocking treatment, extended training of the A-O association (i.e., group FB-BB) attenuated the blocking effect, in comparison with extensive training of the $\mathrm{B}-\mathrm{O}$ control association (i.e., group FB-Con). However, in the control groups for forward blocking (i.e., groups Con-BB and Con-Con), we see that extended posttraining $\mathrm{A}-\mathrm{O}$ pairings did not affect conditioned suppression to $\mathrm{X}$.

An identical 2 (precompound treatment: FB vs. Con) $\times$ 2 (postcompound treatment: BB vs. Con) ANCOVA on the suppression scores in the presence of CS A during testing, using the pre-CS scores as a covariate, showed a main effect of postcompound treatment $\left[F(1,43)=62.87, M S_{\mathrm{e}}=\right.$ $0.08, p<.01]$, as well as an interaction $[F(1,43)=4.27$, $\left.M S_{\mathrm{e}}=0.08, p<.05\right]$. The main effect of precompound treatment was not significant $(p>.65)$. Conditioned suppression to CS A did not significantly differ between groups FB-BB and Con-BB $(p>.25)$. Group FB-Con tended to suppress more strongly to CS A than did group Con-Con, although this difference was only marginally significant $(p>.08)$. More important, conditioned suppression in both groups $\mathrm{FB}-\mathrm{BB}$ and $\mathrm{Con}-\mathrm{BB}$ was weaker than in both groups FB-Con and Con-Con, respectively $[F \mathrm{~s}(1,43)>17.44, p \mathrm{~s}<.01]$.

The results of the test of $X$ in Experiment 2, like those in Experiment 1 , equally support the predictions of SOP-R,

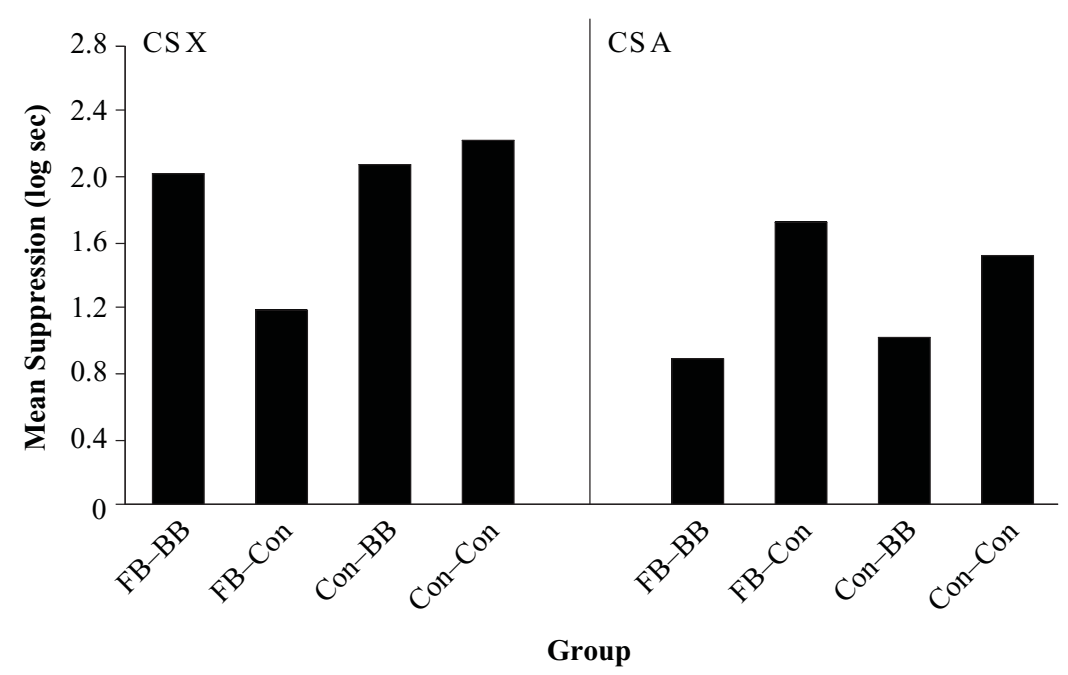

Figure 4. Results of Experiment 2. Left panel: ANCOVA adjusted mean times to complete 5 cumulative seconds of drinking in the presence of the blocked CS (X). Right panel: ANCOVA adjusted mean times to complete 5 cumulative seconds of drinking in the presence of the blocking CS (A). FB, forward-blocking group; BB, backwardblocking group; Con, control group. 
as well as those of the original and extended comparator hypotheses, by showing that forward blocking can also be attenuated by extended $\mathrm{A}-\mathrm{O}$ pairings following the compound trials. However, the results of the test of A in this experiment pose a problem for SOP-R, while supporting the counterintuitive prediction made by the original and the extended comparator hypotheses - namely, that extended training of CS A weakens responding to CS A. Although it is difficult to explain from the view of traditional models of learning (e.g., Rescorla \& Wagner, 1972, or even Dickinson \& Burke, 1996) why extending elemental training with this CS should attenuate, instead of strengthen, responding to it, this result is perfectly compatible with the view of the comparator hypothesis and its extension. In the framework of these models, $\mathrm{A}-\mathrm{O}$ trials strengthened not only the $\mathrm{A}-\mathrm{O}$ association, but also the context- $\mathrm{A}$ and context-O associations. Thus, with extended training of the A-O association, the context became a better comparator stimulus for CS A, and with a sufficient number of trials, the context comes to impair responding to CS A. Impaired responding to CS A is consistent with the extended comparator hypothesis' explanation of attenuation of blocking as being due to the context's becoming a second-order comparator for CS X. It is also consistent with observations made long ago by Pavlov (1927) that greatly extended training can actually weaken conditioned responding.

Because exposure to $\mathrm{O}$ was equated across groups in Experiment 2, differential latent inhibition cannot be responsible for the observed differences in responding to CS X at test. However, it could still be claimed that extended $\mathrm{A}-\mathrm{O}$ pairings in groups $\mathrm{FB}-\mathrm{BB}$ and $\mathrm{Con}-\mathrm{BB}$ resulted in strong latent inhibition to $\mathrm{CS} A$, relative to groups $\mathrm{FB}-\mathrm{Con}$ and $\mathrm{Con}-\mathrm{Con}$, which received extended pairings of an alternative CS (B) with O. Because Experiment 2 lacked appropriate controls for latent inhibition of CS A, this possibility cannot be precluded. In fact, this possibility receives support from the results of the test of A (i.e., weak responding in the groups given extended A-O pairings, but not in the groups given extended $\mathrm{B}-\mathrm{O}$ pairings). However, contrary to differential latent inhibition of $\mathrm{O}$ which raised problems for our interpretation of the results of Experiment 1, latent inhibition of CS A is not problematic at all. Moreover, latent inhibition of CS A can be viewed as the process responsible, according to both the original and the extended comparator hypotheses, for the results of Experiment 2: the context's becoming a first-order comparator stimulus for CS A. According to both the original and the extended comparator hypotheses, in a latent inhibition treatment, the context first forms a strong within-compound association with the CS during the preexposure phase and then, during the acquisition phase, both the CS and the context become associated to O (or the US, in a typical latent inhibition experiment). These three associations (i.e., CS-O, CS-context, and context-O) will conjointly yield weak responding at test of the preexposed CS. Therefore, if one considers our present treatment (extended $\mathrm{A}-\mathrm{O}$ pairings) as resulting in the same three associations as in a latent inhibition treatment (with the only difference being that the context-O association is presumed to be stronger in the case of extended A-O pairings than in a latent inhibition design), the explanation provided by the original and extended comparator hypotheses for the results of Experiment 2 can be viewed as stating that they were due, at least in part, to latent inhibition of the blocking CS.

In contrast, Dickinson and Burke's (1996) SOP-R encounters problems with the assumption that CS A underwent latent inhibition over the course of the extended A-O pairings. In the framework of SOP-R, as in Wagner's (1981) original SOP model, latent inhibition is due to the formation of a context-CS association during CS preexposure, which will cause the context to prime the CS into the A2 state. This activation of the CS in the A2 state will, in turn, result in an impaired A1 activation of the CS. As we previously discussed (see the introduction), SOP-R explains the impact of this treatment on the basis of the formation of an excitatory $\mathrm{X}-\mathrm{O}$ association due to the conjoint $\mathrm{A} 2$ activation of $\mathrm{X}$ and $\mathrm{O}$ during the presentation of CS A after many A-O trials. Also, in order for CS A to associatively activate $\mathrm{X}$ and $\mathrm{O}$ into $\mathrm{A} 2$, CS A must be strongly activated into the A1 state. Therefore, the explanation by SOP-R of attenuation of blocking achieved by extended training of the blocking association necessarily precludes the possibility of latent inhibition to CS A.

In sum, Experiments 1 and 2 provided support for the counterintuitive prediction made by the SOP-R model and by both the original and the extended comparator hypotheses - namely, that extended training of the blocking association following compound training attenuates backward blocking (Experiment 1) and forward blocking (Experiment 2). However, with the exception of the results for the test of A in Experiment 2, which uniquely supported the prediction of the original and extended comparator hypotheses, these experiments are silent on the relative appropriateness of the explanations offered by these accounts concerning the findings in Experiments 1 and 2. Experiment 3 was performed to further explore these accounts, in order to ascertain which of the processes proposed by these theories underlies attenuation of blocking achieved by extended training of the blocking association.

\section{EXPERIMENT 3}

Experiment 2 showed that extended A-O pairings following the compound trials, in addition to attenuating forward blocking, weakened responding to the blocking CS (A). That is, extended training of the $\mathrm{A}-\mathrm{O}$ association both impaired responding to CS A and enhanced responding to CS X. These results of Experiment 2 are most compatible with an explanation of the attenuation of blocking achieved by extended A-O pairings based on a secondorder comparator process, as predicted by the extended comparator hypothesis. Specifically, although the expression of the $\mathrm{X}-\mathrm{O}$ association was initially down-modulated by the $\mathrm{A}-\mathrm{O}$ association, down-modulation of the $\mathrm{A}-\mathrm{O}$ association by the context, due to extended $\mathrm{A}-\mathrm{O}$ pairings, 
could have released responding to CS X from blocking. The reduced responding observed to CS A following the extended $\mathrm{A}-\mathrm{O}$ trials lends support to this account. Alternatively, it is possible that during the extended $\mathrm{A}-\mathrm{O}$ pairings, while the context became a comparator stimulus for CS A, the $\mathrm{A}-\mathrm{X}$ within-compound association underwent extinction. On the basis of this, responding to CS X should also increase as a result of the extended $\mathrm{A}-\mathrm{O}$ trials, but merely because CS X was losing its potential to activate CS A at test. Importantly, these two explanations of the results of the preceding experiments are incompatible because, in order for the context to up-modulate responding to CS X, the $\mathrm{X}-\mathrm{A}$ association must be functional at the time of testing. That is, extinction of Link 2 precludes an explanation of recovery of responding to X based on the context's upmodulating responding to CS X.

Experiment 3 tested which of these alternative explanations offered by the extended comparator hypothesis better accounts for the results of Experiments 1 and 2. According to this theory, if the $\mathrm{X}-\mathrm{A}$ association (Link 2) survived the 200 presentations of CS A without CS X, the down-modulation of $\mathrm{A}-\mathrm{O}$ association (Link 3 ) by the context could be responsible for the recovery of responding to CS X. Thus, if the potential of the context to serve as a comparator stimulus for Link 3 is weakened prior to testing of CS X, the blocking effect should be restored. In order to test this possibility, in Experiment 3 we asked whether the attenuation of backward blocking observed in condition Many in Experiment 1 could be reversed by nonreinforced exposure to the context and, hence, by extinction of the context- $\mathrm{A}$ and context- $\mathrm{O}$ associations, prior to the test on X.

Of critical importance, the manipulation performed in Experiment 3 (i.e., nonreinforced postexposure to the context after extended A-O pairings) also allows us to assess the explanation of the findings of the previous experiments provided by the SOP-R model. According to this model, and contrary to the predictions of the extended comparator hypothesis, extensive context exposure after extended $\mathrm{A}-\mathrm{O}$ training that follows $\mathrm{AX}-\mathrm{O}$ training should not recover the blocking effect. If anything, context exposure should result in an even stronger excitatory $\mathrm{X}-\mathrm{O}$ association, due to the conjoint activation by the context of both $\mathrm{CS} \mathrm{X}$ and $\mathrm{O}$ into the $\mathrm{A} 2$ state, therefore producing stronger responding to CS $\mathrm{X}$ at test (i.e., additional attenuation of blocking).
The design of Experiment 3 is summarized in Table 3. As can be seen in this table, conditions Few and Many in Experiment 1 were replicated in Experiment 3 . Thus, in this experiment, all the groups were first given training with $\mathrm{AX}-\mathrm{O}$ trials, followed by $\mathrm{A}-\mathrm{O}$ trials in condition $\mathrm{BB}$ and by $\mathrm{B}-\mathrm{O}$ trials in condition Control. Orthogonally, the subjects in condition Few were given only either $20 \mathrm{~A}-\mathrm{O}$ trials (group BB-Few) or $20 \mathrm{~B}-\mathrm{O}$ trials (group ControlFew), whereas the subjects in condition Many received $200 \mathrm{~A}-\mathrm{O}$ trials (group BB-Many) or $200 \mathrm{~B}-\mathrm{O}$ trials (group Control-Many). The new groups in this experiment were BB-Many-Ext and Control-Many-Ext. These two groups, following extensive training with either CS A (group BB-Many-Ext) or CS B (group Control-ManyExt) received extinction (Ext) exposure to the training context for a total of $10 \mathrm{~h}$ across multiple sessions.

If exposure to the context alone effectively extinguishes the A-context (i.e., Link 3.2 of Figure 1) and the context$\mathrm{O}$ (i.e., Link 3.3) associations previously formed during extended training of the $\mathrm{A}-\mathrm{O}$ association (i.e., Link 3.1) in group BB-Many-Ext, and if the A-X within-compound association (Link 2.1) survives the large number of presentations of CS A without $\mathrm{X}$ during $\mathrm{A}-\mathrm{O}$ training, blocking of the response elicited by CS X should be reinstated. Alternatively stated, extinction of the context should interfere with the context's potential to down-modulate A's potential as a first-order comparator stimulus for X. That is, weak suppression to CS X should be observed in both groups BB-Few and BB-Many-Ext (but not in group $\mathrm{BB}-\mathrm{Many}$ ), relative to their respective controls. Alternatively, if the $\mathrm{A}-\mathrm{X}$ association was extinguished during extended training of the $\mathrm{A}-\mathrm{O}$ association, responding to CS X should not be affected by context exposure and, hence, strong suppression to $X$ should be observed in group BB-Many-Ext, as well as in group BB-Many, relative to their respective control groups. ${ }^{2}$

Method
Subjects and Apparatus
The subjects were 36 male $(203-304 \mathrm{~g})$ and 36 female (165-
225 g) Sprague Dawley, experimentally naive, young adult rats, bred
in our colony. The subjects were maintained and housed as before.
The apparatus was the same as that in the previous experiments.
Procedure
Unless otherwise mentioned, the procedural aspects in Experi-
ment 3 were identical to those in Experiments 1 and 2 .

Table 3 Design of Experiment 3

\begin{tabular}{lccccc}
\hline \multicolumn{1}{c}{ Group } & Phase 1 & Phase 2 & Phase 3 & Phase 4 & Test \\
\hline BB-Few & $4 \mathrm{AX} \rightarrow \mathrm{O}$ & $20 \mathrm{~A} \rightarrow \mathrm{O}$ & - & $4 \mathrm{O} \rightarrow \mathrm{US}$ & $1 \mathrm{X}$ \\
Control-Few & $4 \mathrm{AX} \rightarrow \mathrm{O}$ & $20 \mathrm{~B} \rightarrow \mathrm{O}$ & - & $4 \mathrm{O} \rightarrow \mathrm{US}$ & $1 \mathrm{X}$ \\
BB-Many & $4 \mathrm{AX} \rightarrow \mathrm{O}$ & $200 \mathrm{~A} \rightarrow \mathrm{O}$ & - & $4 \mathrm{O} \rightarrow \mathrm{US}$ & $1 \mathrm{X}$ \\
Control-Many & $4 \mathrm{AX} \rightarrow \mathrm{O}$ & $200 \mathrm{~B} \rightarrow \mathrm{O}$ & - & $4 \mathrm{O} \rightarrow \mathrm{US}$ & $1 \mathrm{X}$ \\
BB-Many-Ext & $4 \mathrm{AX} \rightarrow \mathrm{O}$ & $200 \mathrm{~A} \rightarrow \mathrm{O}$ & $\mathrm{Ctx}$ & $4 \mathrm{O} \rightarrow \mathrm{US}$ & $1 \mathrm{X}$ \\
Control-Many-Ext & $4 \mathrm{AX} \rightarrow \mathrm{O}$ & $200 \mathrm{~B} \rightarrow \mathrm{O}$ & $\mathrm{Ctx}$ & $4 \mathrm{O} \rightarrow \mathrm{US}$ & $1 \mathrm{X}$ \\
\hline
\end{tabular}

Note-BB, backward blocking; Ext, extinction; A and B, complex tone and white noise, counterbalanced; X, click train; O, flashing light; US, footshock; -, no treatment; Ctx, context exposure for $2.5 \mathrm{~h}$ per session. The numbers denote the number of presentations of each trial type in each phase. 
Acclimation. On Day 1, acclimation proceeded exactly as in Experiments 1 and 2 .

Phase 1. On Day 2, all the groups received four AX-O pairings in a single session.

Phase 2. Days 3-12 consisted of one daily session. On Days 311 , groups BB-Many and BB-Many-Ext received $20 \mathrm{~A}-\mathrm{O}$ pairings per day, whereas groups Control-Many and Control-Many-Ext received $20 \mathrm{~B}-\mathrm{O}$ pairings per day. During these sessions, the animals in groups BB-Few and Control-Few were handled as were the animals in condition Many but received no nominal stimulus presentation or exposure to the training context. On Day 12, groups BB-Few, BB-Many, and BB-Many-Ext received $20 \mathrm{~A}-\mathrm{O}$ pairings, whereas groups Control-Few, Control-Many, and Control-Many-Ext received $20 \mathrm{~B}-\mathrm{O}$ pairings.

Phase 3. On Days 13-16, groups BB-Many-Ext and ControlMany-Ext received daily exposure to the training context for 150 min. The animals in groups BB-Few, Control-Few, BB-Many, and Control-Many were handled the same as the animals in condition Many-Ext but received no context exposure. The chambers were opened every $30 \mathrm{~min}$ of these sessions to ensure that the subjects were awake, which they were (of course, opening the chambers may have contributed to their being awake).

Phase 4. On Day 17, all the groups received four O-US pairings.

Reacclimation. On Days 18 and 19, reacclimation proceeded as in the prior experiments.

Testing. On Day 20, all the groups were tested for conditioned lick suppression to X. The test session proceeded identically to those in Experiments 1 and 2. In this experiment, no subject took longer than $60 \mathrm{sec}$ to complete the first 5 cumulative seconds of drinking prior to the CS presentation.

\section{Results and Discussion}

As can be observed in Figure 5, conditioned suppression to $\mathrm{X}$ was apparently weaker in group BB-Few than in group Control-Few, whereas it was similarly strong in groups BB-Many and Control-Many. More important, group BB-Many-Ext suppressed less than did group Control-Many-Ext in the presence of CS X. These results were supported by the following analyses.
Due to the absence of a complete factorial design (i.e., condition Few-Ext was not included, because it was not of theoretical relevance), separate analyses were performed on the various results of Experiment 3. The first of these analyses included conditions Few and Many and assessed whether the results of Experiment 1 were replicated in Experiment 3 . The second of these analyses was of central importance and assessed whether the backward-blocking effect could be restored (i.e., after its attenuation by extended $\mathrm{A}-\mathrm{O}$ pairings following compound training) by context extinction. The latter analysis included conditions Many and Many-Ext.

Two preliminary ANOVAs were performed in order to examine whether the pre-CS times varied as a function of group during the test with X. First, a 2 (condition: BB vs. Control) $\times 2$ (posttraining trials: Few vs. Many) ANOVA on baseline scores (i.e., times to complete 5 cumulative seconds of drinking prior to CS onset) yielded a marginal effect of number of posttraining trials $[F(1,44)=2.96, p>$ .09] but no main effect of condition and no condition $x$ posttraining trials interaction (all $p \mathrm{~s}>.80$ ). Second, a 2 (condition: BB vs. Control) $\times 2$ (context treatment: Many vs. Many-Ext) ANOVA on the mean latencies in the preCS X period yielded no main effect or interaction (all $p \mathrm{~s}>.50$ ). Due to the marginal effect of posttraining trials in the condition $\times$ posttraining trials ANOVA, we decided to include the pre-CS scores as a covariate in all of the subsequent analyses on the CS scores at test in order to minimize any potential effect that they could have on the critical comparisons.

A 2 (condition: BB vs. Control) $\times 2$ (posttraining trials: Few vs. Many) ANCOVA on the suppression scores in the presence of CS X during testing, using the pre-CS scores as a covariate, yielded a main effect of condition $\left[F(1,43)=9.45, M S_{\mathrm{e}}=0.16, p<.01\right]$ but no main effect of posttraining trials $(p>.10)$. Importantly, the con-

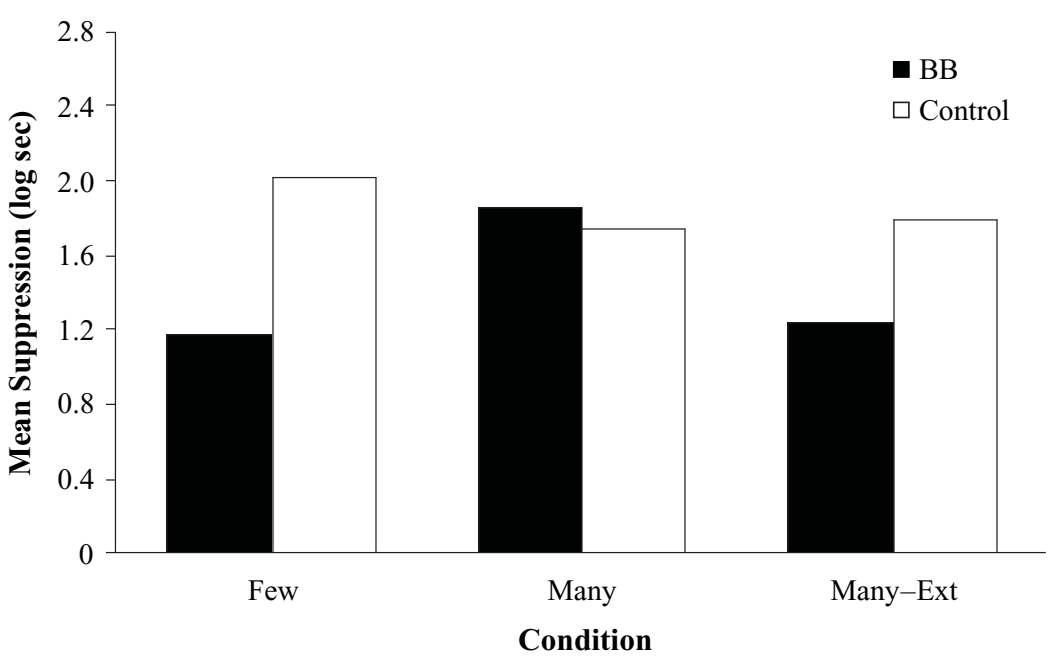

Figure 5. Results of Experiment 3: ANCOVA adjusted mean times to complete 5 cumulative seconds of drinking in the presence of CS X. BB, backward-blocking group; Ext, extinction. 
dition $\times$ posttraining trials interaction was significant $\left[F(1,43)=17.20, M S_{\mathrm{e}}=0.16, p<.01\right]$. As in Experiment 1, planned comparisons showed that conditioned suppression was weaker in group BB-Few than in group Control-Few $[F(1,43)=26.10, p<.01]$, but not in group BB-Many in relation to group Control-Many $(p>$ .45). Also, as in Experiment 1, conditioned suppression was weaker in group BB-Few than in group BB-Many $[F(1,43)=16.46, p<.01]$.

A 2 (condition: BB vs. Control) $\times 2$ (context treatment: Many vs. Many-Ext) ANCOVA on the suppression scores in the presence of CS X during testing, using the pre-CS scores as a covariate, yielded a main effect of context treatment $\left[F(1,43)=5.95, M S_{\mathrm{e}}=0.13, p<.05\right]$, as well as a condition $\times$ context treatment interaction $[F(1,43)=$ 9.97, $\left.M S_{\mathrm{e}}=0.13, p<.01\right]$. The main effect of condition was just short of significant $\left[F(1,43)=3.98, M S_{\mathrm{e}}=0.13\right.$, $p>.052]$. Planned comparisons showed that conditioned suppression to $\mathrm{X}$ was weaker in group BB-Many-Ext than in group Control-Many-Ext $[F(1,43)=13.23, p<$ $.01]$ but was similarly strong in groups BB-Many and Control-Many $(p>.41)$. Also, suppression to $\mathrm{X}$ was weaker in group BB-Many-Ext than in group BB-Many $[F(1,43)=15.58, p<.01]$.

In sum, the results of Experiment 3 replicated and extended those of Experiment 1. As in Experiment 1, the results of Experiment 3 showed evidence of backward blocking after moderate training of the blocking association (i.e., group BB-Few vs. group Control-Few), as well as of attenuation of backward blocking due to extended training of the blocking association (i.e., group BB-Many vs. group Control-Many). More important, in Experiment 3 , backward blocking was also observed in a condition given context extinction after extended training of the blocking association (i.e., group BB-Many-Ext vs. group Control-Many-Ext). This recovery of backward blocking after context exposure (i.e., condition Many-Ext) is explicable only in terms of the extended comparator hypothesis, although posing a problem for both the original comparator hypothesis and Dickinson and Burke's (1996) SOP-R model. According to the extended comparator hypothesis, the context directly down-modulates the expression of the A-O association and indirectly up-modulates responding to CS X. The fact that context exposure following extended training of the A-O association recovered the blocking effect implies that (1) the $\mathrm{X}-\mathrm{A}$ association (Link 2.1) was preserved during the $\mathrm{A}-\mathrm{O}$ trials and (2) context exposure effectively weakened the potential of the context to serve as a comparator stimulus for the A-O association (Link 3.1). As a consequence of this, the blocking CS (A) was released from down-modulation by the context and, consequently, was again itself able to down-modulate responding to CS X, as it was able to do before its extended training with $\mathrm{O}$.

\section{GENERAL DISCUSSION}

The present experiments demonstrated that extended pairings of the blocking CS with the outcome following the compound trials of a blocking preparation attenuates both backward blocking (Experiments 1 and 3) and forward blocking (Experiment 2). The results of Experiment 3 also shed some light on the processes involved in the attenuation of forward and backward blocking in the previous experiments. In Experiment 3, extinction of the training context following extended training of the blocking association restored the blocking effect.

Overall, these results can best be understood from the point of view of the extended comparator hypothesis (Denniston et al., 2001). According to this theory, as a result of $\mathrm{AX}-\mathrm{O}$ training, $\mathrm{CS}$ A was first established as a comparator stimulus for CS X. However, on each subsequent $\mathrm{A}-\mathrm{O}$ pairing, not only the $\mathrm{A}-\mathrm{O}$ association, but also the context- $\mathrm{A}$ and context- $\mathrm{O}$ associations were strengthened. Due to this, with many A-O pairings, the context became an effective comparator stimulus for the A-O association, as is indicated by the results on the test of $\mathrm{A}$ in Experiment 2. More important, this down-modulation of the $\mathrm{A}-\mathrm{O}$ association by the context impaired blocking of the expression of the $\mathrm{CS} \mathrm{X}-\mathrm{O}$ association by CS A, thereby releasing $\mathrm{X}$ from blocking. This explanation of the results of Experiments 1 and 2 by the extended comparator hypothesis was supported by the restoration of backward blocking achieved by exposure to the training context (i.e., extinction) prior to testing (i.e., condition Many-Ext in Experiment 3), which caused the context to lose its potential to down-modulate the A-O association at the time of testing.

None of the other current models that can explain retrospective revaluation effects, such as backward blocking or recovery from overshadowing, can account for the present results. Neither Van Hamme and Wasserman (1994) nor Melchers et al.'s (2004) rehearsal account can explain the very observation of attenuation of blocking caused by extended training of the A-O association in Experiments 1 and 2, a finding that can be readily explained in the framework of Dickinson and Burke's (1996) SOP-R model on the basis of the formation of an excitatory $\mathrm{X}-\mathrm{O}$ association due to CS A's eliciting a stronger $\mathrm{A} 2$ activation of $\mathrm{O}$ during the extended $\mathrm{A}-\mathrm{O}$ pairings following compound training (see the discussion in the introduction). However, SOP-R fails to explain the results of Experiment 3. Even if attenuation of blocking in condition Many was due to CS X's strengthening its excitatory association with $\mathrm{O}$ during the extended $\mathrm{A}-\mathrm{O}$ trials, this account cannot explain why backward blocking was recovered by context exposure in condition Many-Ext.

These experiments provide further evidence of attenuation of forward- and backward-blocking effects achieved by several different posttraining manipulations. The fact that blocking can be attenuated through either extinction of the blocking association (e.g., Arcediano et al., 2001; Blaisdell et al., 1999) or enhancement of the blocking association following the compound trials importantly supports a view of blocking as a failure to express the blocked association at test, as is predicted by both the original and the extended comparator hypotheses. Also, both instances of attenuation of blocking can be explained as being due 
to a weakening in the potential of the blocking association to impair responding to the target CS. However, it must be noted that posttraining extinction and reinforcement of the blocking CS operate through very different mechanisms in the framework of these theories. Extinguishing the CS can be assumed to attenuate blocking through direct extinction of Link 3 and, perhaps, Link 2 (although the present results suggest that Link 2 survived extinction of A). Posttraining A-O trials surely cannot be viewed as extinguishing Link 3, but as impairing its effectiveness on the expression of the $\mathrm{X}-\mathrm{O}$ association, due to the context's serving as an effective comparator stimulus for Link 3 (Experiment 3).

The present results might be viewed as closely related to the prevention of blocking that is achieved by the blocking CS being, in turn, overshadowed (e.g., Denniston, Savastano, Blaisdell, \& Miller, 2003). Specifically, Denniston et al. (2003) found that AX-O trials prior to $\mathrm{XY}-\mathrm{O}$ trials prevented $\mathrm{X}$ from overshadowing the target CS (i.e., CS Y). In their Experiment 4, as in the present experiments, the potential of the first-order comparator (i.e., CS X in Denniston et al.'s [2003] experiment and CS A in our experiments) as a down-modulator of responding to the target CS (i.e., CS Y in Denniston et al.'s [2003] experiment and CS X in our experiments) was impaired by the second-order comparator (i.e., CS A in Denniston et al.'s [2003] experiment and the context in our experiments). Regardless of procedural differences, the behavioral results were similar.

The present results add to the growing list of studies demonstrating that blocking and other stimulus competition effects are highly dependent on the number of trials received by the target and competing associations. For example, Azorlosa and Cicala (1988) showed that the forward-blocking effect wanes as the number of $\mathrm{AX}-\mathrm{O}$ trials increases, an effect that could be explained by the extended comparator hypothesis as the context's becoming a second-order comparator for both Link 2 (i.e., the $\mathrm{X}-\mathrm{A}$ association) and Link 3 (i.e., the $\mathrm{A}-\mathrm{O}$ association). More recently, Stout, Arcediano, Escobar, and Miller (2003) demonstrated that overshadowing is also attenuated when the AX compound is extensively paired with the $\mathrm{O}$. This effect, like the attenuation of blocking due to extended AX-O trials in Azorlosa and Cicala, can also be attributed to the role of the context as a second-order comparator stimulus for the target CS. Stout, Chang, and Miller (2003) supported this view by manipulating the intertrial interval durations, which can be viewed as manipulating the degree of extinction of the context-A and context $-\mathrm{O}$ associations. When the $\mathrm{AX}-\mathrm{O}$ trials were massed and, thus, context extinction was minimized, responding to CS X was strong, presumably because the context effectively up-modulated the expression of the $\mathrm{X}_{-}$ $\mathrm{O}$ association by down-modulating A's potential to downmodulate responding to $\mathrm{X}$. By contrast, in a condition in which AX-O trials were spaced and, hence, contextual extinction was appreciable, responding to CS X was weak, presumably because the context could not up-modulate responding to $\mathrm{CS} \mathrm{X}$.
Finally, as we have previously mentioned, the explanation of the results of the present experiments by the extended comparator hypothesis (i.e., the context's serving as a second-order comparator stimulus for CS X) necessarily implies that the $\mathrm{X}-\mathrm{A}$ within-compound association (Link 2) did not undergo extinction during extended training of CS A with O. The results of Experiment 3 suggest that this within-compound association resisted extinction but was rendered ineffective by the strengthened contextA association. Although this assumption is consistent with the recovery of backward blocking observed in Experiment 3 (i.e., condition Many-Ext), a question arises: Why were 200 presentations of CS A without CS X not effective in extinguishing the $\mathrm{X}-\mathrm{A}$ association? Although the present experiments do not allow us to answer this question, a speculative and post hoc explanation can be entertained. The link formed between CS A and CS X due to their simultaneous presentation either could be a bidirectional association (i.e., $\mathrm{A} \leftrightarrow \mathrm{X}$; see Arcediano, Escobar, \& Miller, 2003, 2005; Arcediano \& Miller, 2002; Gerolin \& Matute, 1999) or could be composed of two independent unidirectional associations (i.e., $A \rightarrow X$ and $X \rightarrow A$ ). In the former case, $\mathrm{A}-\mathrm{O}$ trials would be expected to extinguish the bidirectional association, whereas in the latter case, $\mathrm{A}$ $\mathrm{O}$ trials would be expected to extinguish the $\mathrm{A} \rightarrow \mathrm{X}$ association, but not the $\mathrm{X} \rightarrow \mathrm{A}$ association. The latter scenario, although incompatible with findings from other research, ${ }^{3}$ is consistent with the present observations.

\section{REFERENCES}

Arcediano, F., Escobar, M., \& Matute, H. (2001). Reversal from blocking in humans as a result of posttraining extinction of the blocking stimulus. Animal Learning \& Behavior, 29, 354-366.

Arcediano, F., Escobar, M., \& Miller, R. R. (2003). Temporal integration and temporal backward associations in human and nonhuman subjects. Learning \& Behavior, 31, 242-256.

Arcediano, F., Escobar, M., \& Miller, R. R. (2005). Bidirectional associations in humans and rats. Journal of Experimental Psychology: Animal Behavior Processes, 31, 301-318.

Arcediano, F., \& Miller, R. R. (2002). Some constraints for models of timing: A temporal coding hypothesis perspective. Learning \& Motivation, 33, 105-123.

Azorlosa, J. L., \& Cicala, G. A. (1988). Increased conditioning in rats to a blocked CS after the first compound trial. Bulletin of the Psychonomic Society, 26, 254-257.

Blaisdell, A. P., Gunther, L. M., \& Miller, R. R. (1999). Recovery from blocking achieved by extinguishing the blocking CS. Animal Learning \& Behavior, 27, 63-76.

Chapman, G. B. (1991). Trial order affects cue interaction in contingency judgment. Journal of Experimental Psychology: Learning, Memory, \& Cognition, 17, 837-854.

Denniston, J. C., Miller, R. R., \& Matute, H. (1996). Biological significance as a determinant of cue competition. Psychological Science, 7, 325-331.

Denniston, J. C., Savastano, H. I., Blaisdell, A. P., \& Miller, R. R. (2003). Cue competition as a retrieval deficit. Learning \& Motivation, 34, 1-31.

Denniston, J. C., Savastano, H. I., \& Miller, R. R. (2001). The extended comparator hypothesis: Learning by contiguity, responding by relative strength. In R. R. Mowrer \& S. B. Klein (Eds.), Handbook of contemporary learning theories (pp. 65-117). Mahwah, NJ: Erlbaum.

DiCKInSON, A., \& BURKE, J. (1996). Within-compound associations mediate the retrospective revaluation of causality judgments. Quarterly Journal of Experimental Psychology, 49B, 60-80. 
Gerolin, M., \& Matute, H. (1999). Bidirectional associations. Animal Learning \& Behavior, 27, 42-49.

Kamin, L. J. (1968). "Attention-like" processes in classical conditioning. In M. R. Jones (Ed.), Miami symposium on the prediction of behavior: Aversive stimulation (pp. 9-31). Miami, FL: University of Miami Press.

Kaufman, M. A., \& Bolles, R. C. (1981). A nonassociative aspect of overshadowing. Bulletin of the Psychonomic Society, 18, 318-320.

Larkin, M. J. W., Aitken, M. R. F., \& Dickinson, A. (1998). Retrospective revaluation of causal judgments under positive and negative contingencies. Journal of Experimental Psychology: Learning, Memory, \& Cognition, 24, 1331-1352.

Mackintosh, N. J. (1975). A theory of attention: Variations in the associability of stimuli with reinforcement. Psychological Review, 82, 276-298

MARKMAN, A. B. (1989). LMS rules and the inverse base-rate effect: Comment on Gluck and Bower (1988). Journal of Experimental Psychology: General, 118, 417-421.

Matzel, L. D., Schachtman, T. R., \& Miller, R. R. (1985). Recovery of an overshadowed association achieved by extinction of the overshadowing stimulus. Learning \& Motivation, 16, 398-412.

Melchers, K. G., Lachnit, H., \& Shanks, D. R. (2004). Withincompound associations in retrospective revaluation and in direct learning: A challenge for comparator theory. Quarterly Journal of Experimental Psychology, 57B, 25-53.

Miller, R. R., \& Matute, H. (1996a). Animal analogues of causal judgment. In D. R. Shanks, K. J. Holyoak, \& D. L. Medin (Eds.), The psychology of learning and motivation (Vol. 34, pp. 133-166). San Diego: Academic Press.

Miller, R. R., \& Matute, H. (1996b). Biological significance in forward and backward blocking: Resolution of a discrepancy between animal conditioning and human causal judgment. Journal of Experimental Psychology: General, 125, 370-386.

MilleR, R. R., \& MAtzel, L. D. (1988). The comparator hypothesis: A response rule for the expression of associations. In G. H. Bower (Ed.), The psychology of learning and motivation (Vol. 22, pp. 51-92). San Diego: Academic Press.

Miller, R. R., \& Schachtman, T. R. (1985). Conditioning context as an associative baseline: Implications for response generation and the nature of conditioned inhibition. In R. R. Miller \& N. E. Spear (Eds.), Information processing in animals: Conditioned inhibition (pp. 5188). Hillsdale, NJ: Erlbaum.

Pavlov, I. P. (1927). Conditioned reflexes (G. V. Anrep, Trans.). London: Oxford University Press, Clarendon Press.

Pearce, J. M., \& Hall, G. (1980). A model for Pavlovian learning: Variations in the effectiveness of conditioned but not of unconditioned stimuli. Psychological Review, 87, 532-552.

Rescorla, R. A., \& Wagner, A. R. (1972). A theory of Pavlovian conditioning: Variations in the effectiveness of reinforcement and nonreinforcement. In A. H. Black \& W. F. Prokasy (Eds.), Classical conditioning II: Current research and theory (pp. 64-99). New York: Appleton-Century-Crofts.

Shanks, D. R. (1985). Forward and backward blocking in human contingency judgment. Quarterly Journal of Experimental Psychology, 37B, 1-21.

Stout, S., Arcediano, F., Escobar, M., \& Miller, R. R. (2003). Overshadowing as a function of trial number: Dynamics of first- and second-order comparator effects. Learning \& Behavior, 31, 85-97.
Stout, S. C., Chang, R., \& Miller, R. R. (2003). Trial spacing is a determinant of cue interaction. Journal of Experimental Psychology: Animal Behavior Processes, 29, 23-38.

TAssoni, C. J. (1995). The least mean squares network with information coding: A model of cue learning. Journal of Experimental Psychology: Learning, Memory, \& Cognition, 21, 193-204.

Van Hamme, L. J., \& Wasserman, E. A. (1994). Cue competition in causality judgments: The role of nonpresentation of compound stimulus elements. Learning \& Motivation, 25, 127-151.

WAGNER, A. R. (1981). SOP: A model of automatic memory processing in animal behavior. In N. E. Spear \& R. R. Miller (Eds.), Information processing in animals: Memory mechanisms (pp. 5-47). Hillsdale, NJ: Erlbaum.

Wasserman, E. A., \& Berglan, L. R. (1998). Backward blocking and recovery from overshadowing in human causal judgement: The role of within-compound associations. Quarterly Journal of Experimental Psychology, 51B, 121-138.

\section{NOTES}

1. Assuming that the context was a strong comparator stimulus for CS A does not necessarily imply that the context-US association must be stronger than the CS A association. In fact, there are at least two reasons why the context-US association should have been, if anything, weaker than the A-US association: (1) The context is assumed to be of lower salience than any punctate CS, including CS A, and (2) the context-US association undergoes extinction during the intertrial intervals (i.e., context-alone exposures), whereas punctate CSs do not. At most, after extended A-US pairings, the strength of the context-US association can be assumed to be comparable to that of the A-US association. On the basis of the higher salience of CS A relative to the context, the strength of the A-US association could increase more quickly than that of the context-US association. However, it is possible that after 200 A-US trials, both associations reached the asymptote. In any case, the predictions of the extended comparator hypothesis are not based merely on the relative strengths of the context-US and A-US associations in the condition in which extended A-US trials were given, but on the stronger context-US (and context-A) associations in the condition in which extended A-US training was given, relative to the condition in which few A-US trials were given.

2. A condition in which exposure to an alternative context was received during Phase 3 could provide a control for the context specificity of the treatment received by condition Many-Ext during this phase. In future research, an attempt should be made to assess the role of nonreinforced posttraining exposure to the training context, as opposed to nonreinforced posttraining exposure to a novel context.

3. Paradoxically, contrary to our speculative explanation based on the formation of two independent unidirectional associations (i.e., $\mathrm{A} \rightarrow \mathrm{X}$ and $\mathrm{X} \rightarrow \mathrm{A}$ ), some of the research supporting the notion of bidirectionality of associations (i.e., $\mathrm{A} \leftrightarrow \mathrm{X}$ ) comes from our own laboratory. However, given the large number of differences between the present experiments and those in the other studies, we cannot categorically view our suggested explanation as being at odds with other findings. Although it was not our aim in the present research to examine this issue, it certainly deserves future assessment.

(Manuscript received February 7, 2005; revision accepted for publication May 5, 2005.) 